\title{
Normalizar el conflicto y des-normalizar la violencia: retos y posibilidades de la enseñanza crítica de la historia del conflicto armado colombiano
}

Normalising Conflict and De-Normalising Violence: Challenges and Possibilities of Critical Teaching of the History of the Colombian Armed Conflict

Normalizar o conflito e desnormalizar a violência: retos e possibilidades no ensino crítico da história do conflito armado colombiano

\author{
Angélica Padilla* (iD) orcid.org/0000-0001-6041-6110 \\ Ángela Bermúdez** iD orcid.org/0000-0002-5269-6420
}

\footnotetext{
Artículo de investigación

Revista Colombiana de Educación, N.⒎ 71 Segundo semestre de 2016, Bogotá, Colombia.

Para citar: Padilla, A., y Bermúdez, A. (2016). Normalizar el conflicto y desnormalizar la violencia: retos y posibilidades de la enseñanza crítica de la historia del conflicto armado colombiano. Revista Colombiana de Educación, (71), 219-251.
}

\footnotetext{
Máster en Psicología de la Universidad Nacional de Colombia y actualmente doctoranda del Programa: Derechos Humanos, Retos Éticos, Sociales y Políticos de la Universidad de Deusto (Bilbao, España). Con el apoyo de una beca Erasmus Mundus de la Unión Europea, realiza su investigación Formación de Docentes para la Enseñanza de la Historia de la Violencia Política Reciente: Retos y Oportunidades de la Educación para la Paz en la Escuela bajo la dirección de Angela Bermudez. Se desempeña como asistente de investigación en la línea Conflicto y Culturas de Paz del Centro de Ética Aplicada de Deusto. Correo electrónico: angelica. padilla@deusto.es

** PhD en Educación de la Universidad de Harvard. Coordina la línea de investigación Conflicto y Cultura de Paz del Centro de Ética Aplicada de la Universidad de Deusto (Bilbao, España). Es Investigadora Principal (IP) del estudio internacional Comprensión Crítica de la Violencia Política a través de la Enseñanza de la Historia, financiada por una beca Marie Curie de la Unión Europea (FP7-PEOPLE-2012-CIG) y por una beca de investigación de la Fundación Spencer. Realiza investigación cualitativa en temas de educación ciudadana, para la paz y enseñanza de la historia. Correo electrónico: angeber(a)deusto.es
} 


\section{Resumen}

Este artículo explora la contribución que puede hacer la enseñanza de la historia a procesos de educación para la paz en la escuela, específicamente en el abordaje de la historia del conflicto armado colombiano. Se analizan las narrativas sobre el conflicto presentes en tres textos escolares de historia de amplia difusión, así como en el informe iBasta Ya! Colombia: Memorias de guerra y dignidad del Grupo de Memoria Histórica (GMH, 2O13), haciendo énfasis en (1) la estructura narrativa, (2) las explicación de las causas de la violencia y (3) la representación de la experiencia de las víctimas. Estos elementos narrativos se examinan a la luz de cuatro categorías de la indagación crítica (planteamiento de problemas, escepticismo reflexivo, multiperspectividad y pensamiento sistémico), para determinar la medida en que contribuyen a fomentar una comprensión crítica de la violencia política. El artículo concluye con algunas recomendaciones para una enseñanza de la historia que, en el marco de la educación para la paz, promueva en los estudiantes reflexiones favorables a la deslegitimación de la violencia y a la no repetición.

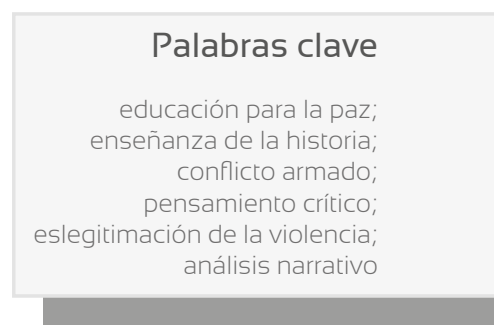

\section{Keywords}

peace education history teaching; armed conflict; critical thinking; delegitimization of violence; narrative analysis

\begin{abstract}
This article explores the contribution history teaching may make toward peace education processes in school, specifically by addressing the history of the Colombian armed conflict. We analyze narratives about the armed conflict which are present in three widely disseminated history school textbooks, as well as the iBasta Ya! Colombia: Memories of War and Dignity Report, drafted by the Historical Memory Group (смн, 2013). Our analysis emphasizes: (i) narrative structure, (ii) explanation of the causes of violence, and (iii) the representation of victims' experience. We examine these narrative elements in light of four critical inquiry categories (Problem Posing, Reflexive Scepticism, Multiperspectivity and Systemic Thinking), in order to establish the extent to which the former help foster a critical understanding of political violence. The article ends with some recommendations for a kind of history teaching capable of nurturing -in the framework of peace education-reflections that favor delegitimization of violence and non-repetition.
\end{abstract}

\section{Resumo}

Este artigo explora a contribuição que pode fazer a educação da história á processos de educação para a paz na escola, principalmente na abordagem da história do conflito armado colombiano. Analisam-se as narrativas sobre o conflito presentes em três textos da escola da amplia difusão, assim como no informe ¡Basta Ya! Memorias de guerra y dignidad do Grupo de Memória Histórica (GMH, 2013), fazendo ênfase em (1) a estrutura narrativa, (2) a explicação das causas da violência y (3) a representação da experiência das vitimas. Estes elementos narrativos se examinam á luz de quatro categorias da indagação crítica (problematização, ceticismo reflexivo, multiperspectividade e pensamento sistêmico), para determinar a medida na que ajudam á incentivar uma compreensão crítica da violência política. O artigo termina com algumas recomendações para um ensino da história que, no marco duma educação para a paz, promova nos estudantes reflexões favoráveis á dês legitimação da violência e á não repetição.

\section{Palavras chave}

educação para a paz; ensino da história; conflito armado; pensamento crítico; dês legitimação da violência; analise narrativo 


\section{Introducción}

a sociedad colombiana se encuentra hoy ante una oportunidad histórica única, que puede ayudarle a cerrar un capítulo de más de cinco décadas que ha dejado cerca de 220000 muertos y alrededor del $10 \%$ de la población desplazada de sus territorios (Wills, 2015). Al escribir este artículo, estamos a pocos meses de culminar tres años de un complejo proceso de negociación entre el Estado colombiano y las Fuerzas Armadas Revolucionarias de Colombia (FARC). Desde octubre de 2012, con las negociaciones de La Habana se ha buscado acordar los términos que permitan ponerle fin al conflicto armado y sentar las bases para una paz sostenible. Los diálogos han contado con la participación sin precedentes de otros actores del conflicto, como víctimas, militares, empresarios y académicos. El proceso de La Habana es, a ojos de muchos, bastante más promisorio que cualquiera de los anteriores intentos de "negociar la paz", y la posibilidad de desmovilizar a la guerrilla más grande y más vieja del país se ve cercana y plausible. Sin embargo, sabemos bien que lo más difícil está por comenzar. ¿Cómo vamos a proyectar un futuro en paz desde un pasado y un presente tan marcados por la violencia? La complejidad de este reto se insinúa en el uso recurrente del término posconflicto para referirse al escenario posterior a la firma de los acuerdos. De firmarse estos, cesarán parte de los enfrentamientos armados $^{1}$. Pero nos quedaremos precisamente con el conflicto, o mejor, con múltiples conflictos enraizados en la estructura social y en la cultura de la sociedad colombiana. El cese de los enfrentamientos armados no debe generar la falsa ilusión de que ya no hay conflicto, ni debe invisibilizar las muchas otras violencias que lo alimentan y se alimentan de él en un círculo vicioso voraz.

Los acuerdos de La Habana resaltan el tipo de transformaciones necesarias para desenraizar el conflicto armado de las estructuras sociales, económicas y políticas: desarrollo agrario, participación política, política de drogas y reparación a las víctimas. Pero ¿cómo vamos a desenraizarlo de la cultura política del país? Los resultados de las últimas jornadas electorales muestran una opinión pública dividida en su apoyo al proceso de paz, lo cual sugiere que amplios sectores de población endorsan la vía de la guerra. Algunos porque creen en la legitimidad de la violencia como medio para "solucionar el conflicto", otros porque los asalta el temor ante los riesgos de relajar la "mano dura". El reto es que tras la firma de los acuerdos tendremos una sociedad atravesada por profundos conflictos sociales, pero también una sociedad que ha sido muy reacia a reconocer la raíz de estos conflictos y que se ha acostumbrado a recurrir a la violencia para

1 Aún no es claro qué vaya a pasar con los otros grupos guerrilleros y bandas criminales. 
resolverlos de tajo. Por eso, lo que tenemos que desenraizar de la cultura es la asociación automática entre conflicto y violencia. Esto no es condición suficiente, pero sí necesaria para que un proceso de paz sea sostenible y para que las iniciativas de manejo no-violento de los conflictos que llevan décadas germinando en el país puedan florecer sin tener que enfrentarse al terror o la invisibilización.

Este gran reto nos compete directamente a los educadores, a todos, pero particularmente a los profesores de ciencias sociales. En nuestras manos está ayudarles a las nuevas generaciones a entender críticamente la historia del país, de manera tal que se normalice el conflicto y se des-normalice la violencia. Por eso nos preguntamos: ¿Cómo debe enseñarse la historia del conflicto armado? ¿Qué manera de contar esa historia es más propicia para la construcción de la paz?

En este artículo contrastamos dos formas distintas de contar la historia del conflicto armado colombiano. Por un lado, analizamos los relatos que aparecen en tres textos recientes de historia para 9. ${ }^{\circ}$ grado $^{2}$, y por otro lado lo contrastamos con el relato que presenta el informe iBasta Ya! Colombia: memorias de guerra y dignidad (Gмн, 2013).

Estos son, sin duda, materiales de muy distinta naturaleza, por lo que la intención de contrastar sus relatos merece una explicación. Los textos escolares siguen los lineamientos curriculares oficiales del Ministerio de Educación Nacional, que requieren fomentar una diversidad de competencias y cubrir grandes cantidades de temas de las ciencias sociales en los contextos nacional, regional e internacional. Son producidos y vendidos por reconocidas editoriales comerciales que compiten por un nicho en el mercado de material educativo, especialmente en un contexto como el colombiano en el que el uso de textos no es obligatorio. Por su parte, el informe iBasta Ya!, publicado por el Centro Nacional de Memoria Histórica en el 2013, es un documento de difusión pública de la investigación realizada por el Grupo de Memoria Histórica en el marco de la Ley de Víctimas y Restitución de Tierras (Ley 1448 del 2011). Aunque este informe no se produjo como un material para el trabajo en el aula, sí puede decirse que se pensó como un material que sirviera para educar a la opinión pública en su comprensión del conflicto. En sus cerca de cuatrocientas páginas, el informe usa un lenguaje relativamente sencillo, está ampliamente ilustrado con fotografías y figuras, y su diagramación generosa facilita su lectura.

Comparar los relatos de los textos escolares con el relato generado tras un proceso de investigación académica podía parecer injusto o inadecuado, dado que sus objetivos, autoría, contenidos, formato y mecanismos de

2 El sistema educativo colombiano consta de 11 grados. $9^{\circ}$ grado es el último año del ciclo de educación básica secundaria, al que siguen dos años de educación media. 
circulación son necesariamente distintos. Pero son justamente estas diferencias las que motivan el ejercicio que proponemos en este artículo. En el contexto actual, y con la perspectiva de esclarecer las maneras de enseñar la historia del conflicto que son más propicias para la construcción de una paz sostenible, lo que buscamos es precisamente examinar formas distintas de narrar la historia del pasado violento. Los textos escolares, como ocurre en otros lugares, cumplen la función de ofrecer una síntesis, por fuerza apretada y general, de la historia nacional; y no se han escrito con preguntas sobre el conflicto, la violencia y la paz en mente. En cambio, el informe iBasta Ya!, con todas las limitaciones que pueda tener, representa el esfuerzo de un grupo de investigadores por mirar al pasado y narrar una historia violenta con miras a construir un horizonte de paz. ¿Cómo cambian entonces los relatos cuando las preguntas explícitas sobre el conflicto, la violencia y la paz adquieren un lugar protagónico? ¿En qué medida marcan estos distintos relatos las posibilidades de desarrollar en los jóvenes una comprensión crítica de la violencia?

El análisis que presentamos se centra en tres aspectos: (1) la estructura del relato, (2) la explicación de las causas de la violencia y (3) la representación de la experiencia de las víctimas. En la discusión de resultados planteamos cómo estos aspectos constituyen elementos fundamentales en la construcción de narrativas que normalicen o des-normalicen la violencia, y por lo tanto fundamentales a la hora de desarrollar una comprensión crítica del pasado, favorable a la construcción de culturas de paz (Bermúdez, 2016). La coyuntura promisoria del actual proceso de paz resalta la urgencia de abordar los retos y posibilidades que discutimos en este artículo, pero en realidad es la larga historia de violencia, destrucción, trauma y desesperanza lo que lo hacen importante.

\section{Consideraciones desde la literatura}

Este estudio se fundamenta en distintos cuerpos de literatura sobre la enseñanza de la historia y la educación para la paz, y en la creciente articulación de estos dos campos de investigación (Barton \& Levstik, 2004; Bermúdez, 2015; Carretero, Haste \& Bermúdez, 2016; Cole, 2007; Herrera \& Rodríguez, 2012; McCully, 2012; Pagès, 2003; Sears, 2011).

En la producción reciente de ambos campos destaca la investigación sobre el papel que desempeñan las narrativas en la comprensión de los fenómenos sociales. Retomando las teorías fundacionales de Bruner (1990, 1991) y Vygotsky (1978) sobre cómo los individuos estructuran el sentido de sí mismos y de su realidad a través del "pensamiento narrativo", diversos investigadores han estudiado los procesos por los cuales las personas adoptan narrativas disponibles en sus contextos socioculturales como marcos de referencia para construir su comprensión de cuestiones sociales 
actuales o del pasado, y orientan su propia acción ante ellas (Andrews, 2007; Haste \& Abrahams, 2008; Wertsch, 1997). Según Haste (1993), estas narrativas se convierten en teorías sociales que definen qué se da por sentado y qué se cuestiona, qué se considera "natural" o "normal" y qué se ve como "problemático". Así, las narrativas ayudan a establecer coherencia entre las identidades y experiencias individuales y colectivas. La investigación sobre procesos narrativos en la educación para la paz se ha concentrado en explicar cómo las narrativas sociales afectan la manera en que los individuos explican situaciones de conflicto, construyen representaciones sobre "el otro" a partir de las cuales interpretan sus acciones, y justifican cómo ellos mismos se relacionan con sus "oponentes" (Bar-Tal, 2000; Bekerman \& Zembylas, 2012; Salomon, 2004). Diversos estudios de caso ilustran estos procesos y sus consecuencias en sociedades profundamente divididas o enfrentadas, como Irlanda del Norte, Israel, Palestina, Croacia, Chipre o Ruanda (Barber, 2009; Raviv, Oppenheimer \& Bar-Tal, 1999; Salomon \& Nevo, 2005).

En el campo de la enseñanza y el aprendizaje de la historia, investigadores en diversos países han estudiado la manera en que los textos escolares definen versiones "oficiales" y "no-oficiales" del pasado, haciendo que las narrativas históricas escolares estén frecuentemente vinculadas con la construcción de imaginarios colectivos y discursos nacionales dominantes, que los poderes que regulan la educación buscan instaurar en los ciudadanos (Carretero, 2011; Carretero, Asensio \& Moneo, 2012; Ferro, 1984; Gómez, 2015; Acevedo \& Samacá, 2012; Nash, Crabtree \& Dunn, 1997; Symcox \& Wilschut, 2009). Según Wertsch (2004), los relatos específicos que encontramos en los textos reflejan plantillas narrativas esquemáticas subyacentes que organizan los distintos relatos sobre el pasado en torno a temas o conceptos dominantes, por ejemplo la construcción de la nación, el progreso o la conquista de la libertad. Por ejemplo, Tulviste \& Wertsch (1994) describen este fenómeno en el caso de Estonia, particularmente desde la caída del Muro de Berlín y el colapso de la Unión Soviética. Otros estudios muestran cómo las narrativas escolares manejan las tensiones existentes entre las perspectivas de grupos dominantes y marginales, o mayoritarios y minoritarios y sus consecuencias en contextos de conflicto y reconciliación (Clark, 2006; Kitson, 2007; Oglesby, 2007).

Aunque muchos de los estudios narrativos en educación para la paz y enseñanza de la historia se han desarrollado sin mayor diálogo entre sí, hay coincidencias importantes. Entre ellas cabe destacar el reconocimiento de: (1) el carácter interpretativo, plural y controversial de las narrativas sociales e históricas; (2) la estrecha relación entre el uso de narrativas sociales y la construcción de identidades individuales y colectivas; (3) la compleja relación entre las narrativas históricas, la memoria 
colectiva y la explicación histórica disciplinar, y (4) las relaciones de poder que configuran la producción y el consumo de narrativas.

Estas coincidencias subyacen a una línea de investigación que ha cobrado especial fuerza en los últimos años y que explora los procesos de enseñanza y aprendizaje de "historias difíciles", bien sea porque se refieren a hechos sobre los que hay fuertes disputas entre versiones encontradas, o porque tratan episodios del pasado especialmente violentos y traumáticos (Barton \& McCully, 2005; Epstein, 2009; Herrera \& Rodríguez, 2012; Vélez \& Herrera, 2014; Zembylas, 2014). Estos estudios evidencian los retos que surgen al enfrentar la complejidad ética, emocional e intelectual de los episodios incómodos del pasado (Bekerman \& Zembylas, 2012; Garrett, 2011; Savenije, Van Boxtel \& Grever, 2014; Sheppard, Katz \& Grosland, 2015), que han Ilevado a algunas sociedades en "posconflicto" a considerar opciones como "pasar la página y mirar al futuro", o suspender temporalmente la enseñanza de la historia del conflicto mientras se decanta el sufrimiento y la polarización social. Sin embargo, estos autores también destacan las oportunidades que la exploración reflexiva de estas "historias difíciles" abre para los procesos de construcción de paz y la reconciliación.

Estas oportunidades requieren una enseñanza de la historia dispuesta a analizar los conflictos en toda su complejidad, multivocal y abierta a la exploración de cuestiones controversiales (Barton \& McCully, 2007; Galtung, 1996; Hess, 2009; Shaheed, 2013). Por ello, diversos autores coinciden en la importancia de articular la enseñanza de la historia y la educación para la paz con el desarrollo del pensamiento crítico (Bajaj, 2008; Bermúdez, 2012; 2015; Wenden, 2007) que permita a los estudiantes desarrollar una comprensión más sofisticada de las causas, dinámicas y consecuencias de los conflictos sociales, reconocer empáticamente la experiencia de diversos actores y construir posiciones independientes sobre las opciones para abordar los conflictos.

El énfasis en el pensamiento crítico es especialmente notorio en los enfoques de educación para la paz que abordan la perspectiva de las víctimas, las raíces estructurales que causan el conflicto y la violencia (incluidas cuestiones de justicia social y la violación de derechos humanos), así como la capacidad de agencia transformadora de individuos y comunidades (Bajaj, 2008; Etxeberria, 2013; Galtung, 1996; Galtung, 1998; Reardon, 1988). Estos enfoques consideran que en contextos permeados por la violencia, además de trabajar en cuestiones como el desarrollo de habilidades interpersonales para la resolución de conflictos, o el reconocimiento y la valoración de la diversidad, la educación para la paz supone, esencialmente, comprender y desaprender la guerra (Bastida, 1994; Bastida, Lugo \& Rocasalbas, 2008). Así, la escuela debe afrontar directamente las subjetividades y polarizaciones configuradas en contextos de guerra, y generar

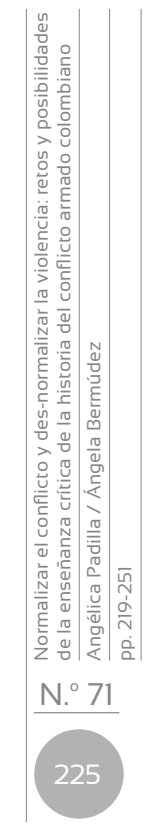


reflexión sobre imaginarios que se encuentran profundamente arraigados en la memoria colectiva de las comunidades, cargados de emociones asociadas al dolor y al miedo (Lizarralde, 2012; Salomon \& Nevo, 2005).

Por su parte, en el campo de la enseñanza y aprendizaje de la historia hay distintas vertientes en la conceptualización del pensamiento crítico. Una rica tradición de investigación sobre el desarrollo de procesos de pensamiento propios de la disciplina histórica entiende el pensamiento crítico como aquel que les permite a los estudiantes construir y examinar explicaciones sobre cuestiones del pasado de manera rigurosa (Dickinson, Lee \& Rogers, 1984; Shemilt, 1980; Wineburg, 2001). Estos estudios muestran cómo niños y jóvenes aprenden a analizar e interpretar fuentes documentales, razonar sobre las evidencias que soportan distintos argumentos, identificar y entretejer relaciones causales, rastrear procesos de cambio y continuidad, o reconstruir diversas perspectivas en sus propios contextos de sentido. Algunos investigadores argumentan que el pensamiento crítico es la piedra angular que permite articular el conocimiento del pasado con la comprensión de problemas y cuestiones sociales relevantes del presente (Barton \& Levstik, 2004; Bermúdez, 2015; Seixas, 2004; Seixas \& Morton, 2013). Desde una perspectiva distinta pero complementaria, otros investigadores conciben la historia crítica como aquella que les ayuda a los estudiantes a problematizar éticamente las condiciones actuales de vida, orientando la exploración del pasado para comprender la configuración del presente, sus actores y sus perspectivas de transformación (Ávila, 2012; Gómez, 2015; Herrera \& Cristancho, 2013; Herrera \& Rodríguez, 2012). Estos autores enfatizan también el rol del pensamiento crítico, la clarificación de las diferencias y las relaciones complejas entre la memoria oficial, las diversas memorias colectivas, y las explicaciones históricas académicas.

Nuestra investigación integra estos distintos cuerpos de literatura en el análisis de narrativas sobre procesos históricos particularmente marcados por la violencia. Lo hacemos buscando clarificar distintos mecanismos a través de los cuales estas narrativas fomentan o impiden una comprensión crítica que ayude a des-normalizar y deslegitimar la violencia, y en esa medida, aportar a la construcción de la paz.

\section{Metodología}

Este estudio forma parte de una investigación cualitativa internacional sobre la relación entre la enseñanza de la historia y la legitimación o deslegitimación de la violencia política. En la primera fase se analizaron las narrativas sobre nueve hechos históricos violentos que aparecen en textos escolares y otros materiales educativos de Colombia, España y Estados Unidos. El conflicto armado fue uno de los tres temas analizados 
en Colombia. El diseño conceptual y metodológico que empleamos en este artículo se deriva de este proyecto más amplio.

Para la recolección de datos se seleccionaron tres textos escolares de historia, de publicación reciente y en uso actualmente en las aulas. Los tres textos siguen las directrices curriculares oficiales, y están dirigidos a estudiantes de noveno grado, curso en el que se cubre más ampliamente el tema del conflicto armado colombiano. Se buscaron los textos de reconocidas editoriales para que tuvieran amplia difusión. Siguiendo estos criterios se seleccionaron los textos de historia y ciencias sociales para noveno grado de las editoriales Norma (2011), SM (2012) y Santillana (2013). De cada texto se seleccionó el capítulo correspondiente al periodo que va desde mediados del siglo xx hasta la actualidad, en el que se trata este tema. Cada capítulo tiene una extensión aproximada de 25 páginas, dentro de las cuales el tema del conflicto armado colombiano ocupa aproximadamente una cuarta parte.

Para contrastar las narrativas de los textos escolares se eligió el informe ¡Basta Ya! Colombia: memorias de guerra y dignidad del Grupo de Memoria Histórica (GMH, 2013) publicado por el Centro Nacional de Memoria Histórica ${ }^{3}$. Siguiendo los criterios establecidos en el proyecto de investigación más amplio, este material de contraste debía ofrecer un ejemplo de narrativa alternativa a la de los textos escolares, al no estar determinado por las directrices curriculares oficiales. En cuanto a la autoría, debía proceder de centros académicos u organizaciones que tuvieran dentro de su misión y objetivos promover la cultura histórica, los derechos humanos o la construcción de la paz. Aunque dicho material no tenía que haber sido diseñado explícitamente para su uso en el aula, si debía tener una función educativa general. Del informe ¡Basta Ya! se seleccionaron para el análisis tres capítulos que abordan (1) las dimensiones y modalidades de la violencia, (2) los orígenes, dinámicas y crecimiento del conflicto armado, y (3) los impactos y daños causados por el mismo. Cada capítulo tiene aproximadamente 80 páginas, aunque cerca de una tercera parte la ocupan fotografías y gráficos. El material publicado por el CNMH no es, por supuesto, la única forma alternativa de narrar la historia del conflicto armado colombiano, pero elegimos enfocar nuestro análisis en él dada su envergadura y visibilidad. Entre otras consideraciones, tuvimos en cuenta que el CNMH a través de un convenio con el Ministerio de Educación Nacional desempeña un rol fundamental en el diseño e implementación de estrategias educativas para la reconstrucción de la memoria histórica del conflicto armado colombiano y la educación para la paz.

3 A partir de su publicación en el 2013 el Centro Nacional de Memoria Histórica (CNMH) ha desarrollado otros materiales para la escuela, que en lo fundamental siguen el mismo enfoque y estructura narrativa. Dado que estos otros materiales no estaban terminados cuando hicimos este análisis, optamos por analizar el informe ¡Basta Ya!

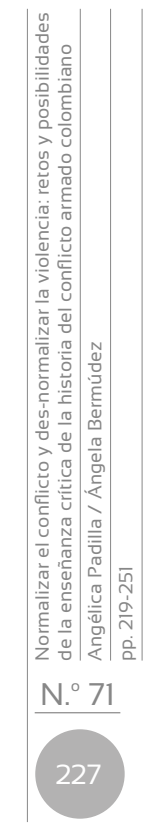


En el análisis de datos se utilizaron tanto estrategias de codificación inductivas como otras orientadas teóricamente (Saldaña, 2012). En primer lugar, todos los materiales fueron codificados inductivamente para identificar los temas sobresalientes en la descripción de acontecimientos y actores. Además, revisamos los títulos y subtítulos de los textos, e hicimos una consulta de frecuencia de palabras. Posteriormente, el análisis siguió un conjunto de preguntas analíticas que se diseñaron para examinar los temas históricos del proyecto internacional y poder hacer comparaciones entre países, temas o recursos educativos.

Tabla 1. Preguntas analíticas

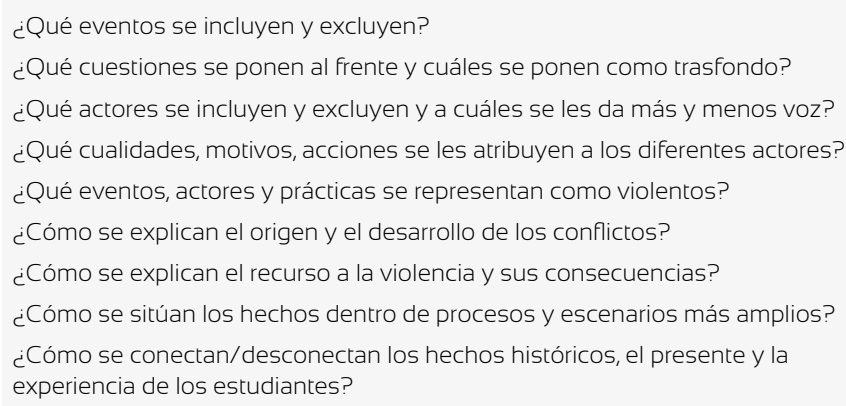

A partir de estos análisis se construyeron perfiles narrativos (Maxwell, 2013; Miles \& Huberman, 1994) que sintetizan cómo cada relato representa el conflicto armado colombiano y la violencia inherente al mismo. Finalmente, los perfiles narrativos fueron examinados a la luz de cuatro herramientas de la indagación crítica (Bermúdez, 2015) para identificar en qué medida permiten una comprensión problematizante, reflexiva, multivocal y sistémica del conflicto y del uso de la violencia.

Tabla 2. Herramientas de la indagación crítica

\begin{tabular}{l|l}
\hline $\begin{array}{c}\text { Herramienta de } \\
\text { indagación crítica }\end{array}$ & \multicolumn{1}{c}{ Procesos / Operaciones Intelectuales } \\
\hline $\begin{array}{l}\text { Planteamiento de } \\
\text { problemas }\end{array}$ & $\begin{array}{l}\text { Reconocimiento de acertijos intelectuales, dilemas morales y } \\
\text { controversias sociales. } \\
\text { Reconocimiento de emociones como fuentes de conocimiento } \\
\text { Planteamiento de preguntas que invitan a indagar más a fondo. }\end{array}$ \\
\hline $\begin{array}{l}\text { Escepticismo } \\
\text { reflexivo }\end{array}$ & $\begin{array}{l}\text { Duda e indagación metódica sobre preguntas de validez y verdad. } \\
\text { Escrutinio de supuestos, argumentos y procesos de razonamiento. }\end{array}$ \\
\hline
\end{tabular}




\begin{tabular}{l|l}
$\begin{array}{c}\text { Herramienta de } \\
\text { indagación crítica }\end{array}$ & \multicolumn{1}{c}{ Procesos / Operaciones Intelectuales } \\
\hline Multi-perspectividad & $\begin{array}{l}\text { Identificación y coordinación de perspectivas relevantes. } \\
\text { Contextualización de perspectivas (preservar significado). } \\
\text { Reconstrucción de dilemas, controversias y relatos multi-vocales. }\end{array}$ \\
\hline Pensamiento & $\begin{array}{l}\text { Deconstrucción/reconstrucción de sistemas, procesos y } \\
\text { secanismos causales. } \\
\text { Coordinación de estructuras y agencia humana en las explicaciones. } \\
\text { Representación de la totalidad, complejidad y transformación } \\
\text { de los fenómenos. }\end{array}$ \\
\hline
\end{tabular}

Fuente: adaptado de Bermúdez (2015).

Durante todo el proceso, tres investigadores leyeron y codificaron los datos por separado, y se reunieron para comparar, discutir y llegar a codificaciones y reconstrucciones narrativos mutuamente aceptables.

\section{Resultados}

En esta sección discutiremos los resultados del análisis, que hemos organizado en tres categorías: (1) la estructura del relato, (2) la explicación de las causas del conflicto y de la violencia y (3) la representación de la experiencia de las víctimas. A partir del análisis inductivo de temas sobresalientes y de la exploración guiada por preguntas analíticas, encontramos que los tres textos tienen un relato común, que es diferente del de ¡Basta Ya!. Por ello, en la presentación de resultados, contrastaremos dos formas de narrar la historia del conflicto armado colombiano.

\section{Estructura de los relatos}

La primera diferencia entre los dos relatos es la estructura narrativa y el consiguiente énfasis temático. Por estructura narrativa nos referimos a los hechos y actores que se incluyen y excluyen, a la forma en que se organizan estos contenidos, y a los aspectos que se enfatizan o por el contrario se presentan como secundarios o marginales. Los textos escolares tienen una estructura cronológica lineal, vertebrada por la secuencia de los periodos presidenciales y las políticas y acciones de los gobiernos. El ;Basta Ya! tiene una estructura explicativa que se asemeja a una red en la que se entretejen distintos factores causales en el proceso de configuración del conflicto, las diversas manifestaciones, usos y transformaciones de la violencia, sus consecuencias, y la experiencia y perspectiva de los distintos actores, particularmente las víctimas.

El impacto de estas estructuras narrativas en los énfasis temáticos se evidencia en la frecuencia de algunas palabras en proporción a la cantidad 
de texto de cada narrativa. Según arroja una búsqueda en NVivo, las cinco palabras más frecuentes en los textos escolares son, en su orden: Gobierno, nacional, Colombia, política y país. En el ¡Basta Ya! las palabras son: violencia, guerra, nacional, justicia y víctimas.

Figura 1. Marca de Nube NVivo de las 25 palabras más frecuentes de cada narrativa.

\begin{tabular}{|c|c|}
\hline Narrativa textos escolares & Narrativa ¡Basta Ya! \\
\hline 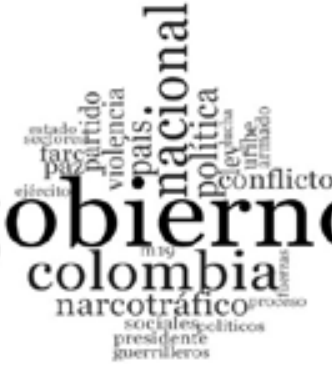 & 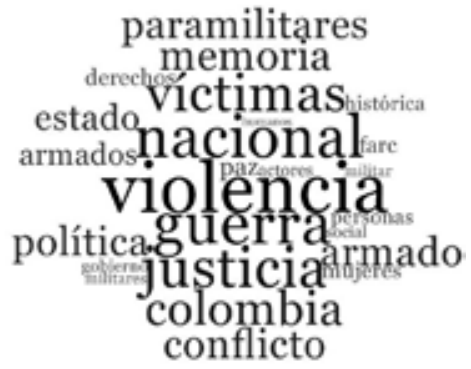 \\
\hline
\end{tabular}

\section{Estructura narrativa en los textos escolares}

En los tres capítulos de los textos se describen las políticas y acciones de cada gobierno en distintos ámbitos, como el desarrollo económico, la vida política electoral, la gestión administrativa e institucional, o la política social e internacional. En ellos se aborda al conflicto armado colombiano relatando el surgimiento y accionar de distintos grupos al margen de la ley, y las consiguientes acciones emprendidas por los gobiernos para contenerlos, combatirlos o propiciar la paz. Los textos varían en el nivel de detalle con el que describen a los actores y los hechos, y en algunos casos en el enfoque que adoptan al tocar algunos temas. Sin embargo, hay un cuerpo de hechos de cada presidencia que son comunes a los tres textos y vertebran la representación del conflicto armado. En la tabla 3 se resumen los hechos incluidos en la narrativa central de los tres textos escolares. El lenguaje se mantiene cercano al de los textos.

Tabla 3. Hechos históricos que conforman la narrativa en los textos escolares

\begin{tabular}{|l|l|}
\hline \multicolumn{1}{|c|}{ Periodo presidencial } & \multicolumn{1}{c|}{ Hechos históricos del conflicto armado comunes a tres textos } \\
\hline $\begin{array}{l}\text { A. Lleras Camargo } \\
\text { (1958-1962) }\end{array}$ & $\begin{array}{l}\text { Repartición del poder entre liberales y conservadores (Frente Nacional) } \\
\text { que se traduce en exclusión política. } \\
\text { Conformación de distintas fuerzas de oposición, tanto políticas como } \\
\text { armadas. }\end{array}$ \\
$\begin{array}{l}\text { G. León Valencia } \\
\text { (1962-1966) }\end{array}$ & $\begin{array}{l}\text { Surgimiento de grupos armados al margen de la ley (FARC, ELN, EPL, } \\
\text { MAQL, M19) en el contexto internacional de la Guerra Fría y las nuevas } \\
\text { ideologías de izquierda. }\end{array}$ \\
\hline $\begin{array}{l}\text { C. Lleras Restrepo } \\
\text { (1966-1970) }\end{array}$ & \\
\hline $\begin{array}{l}\text { M. Pastrana Borrero } \\
\text { (1970-1974) }\end{array}$ & \\
\hline
\end{tabular}




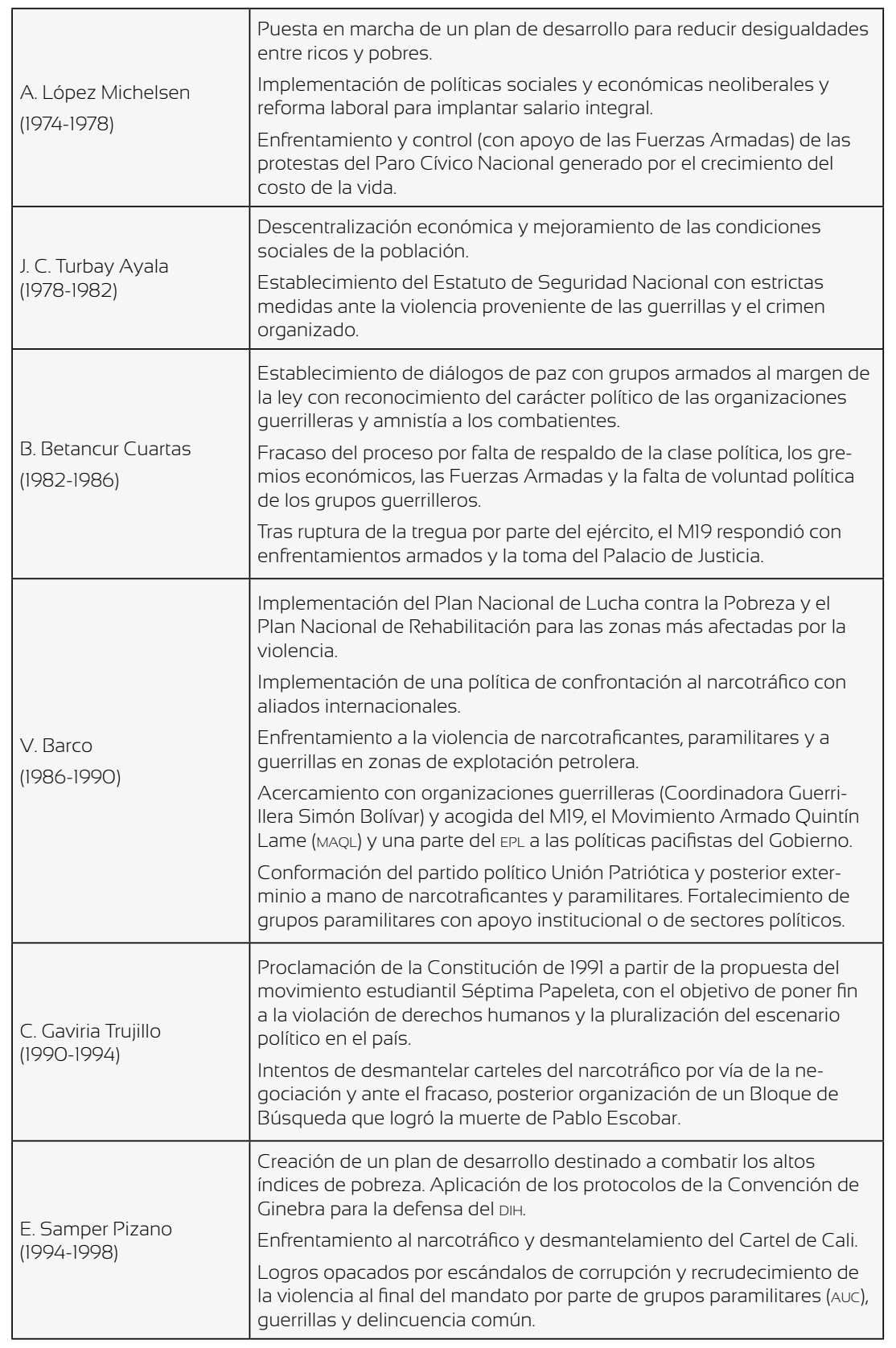




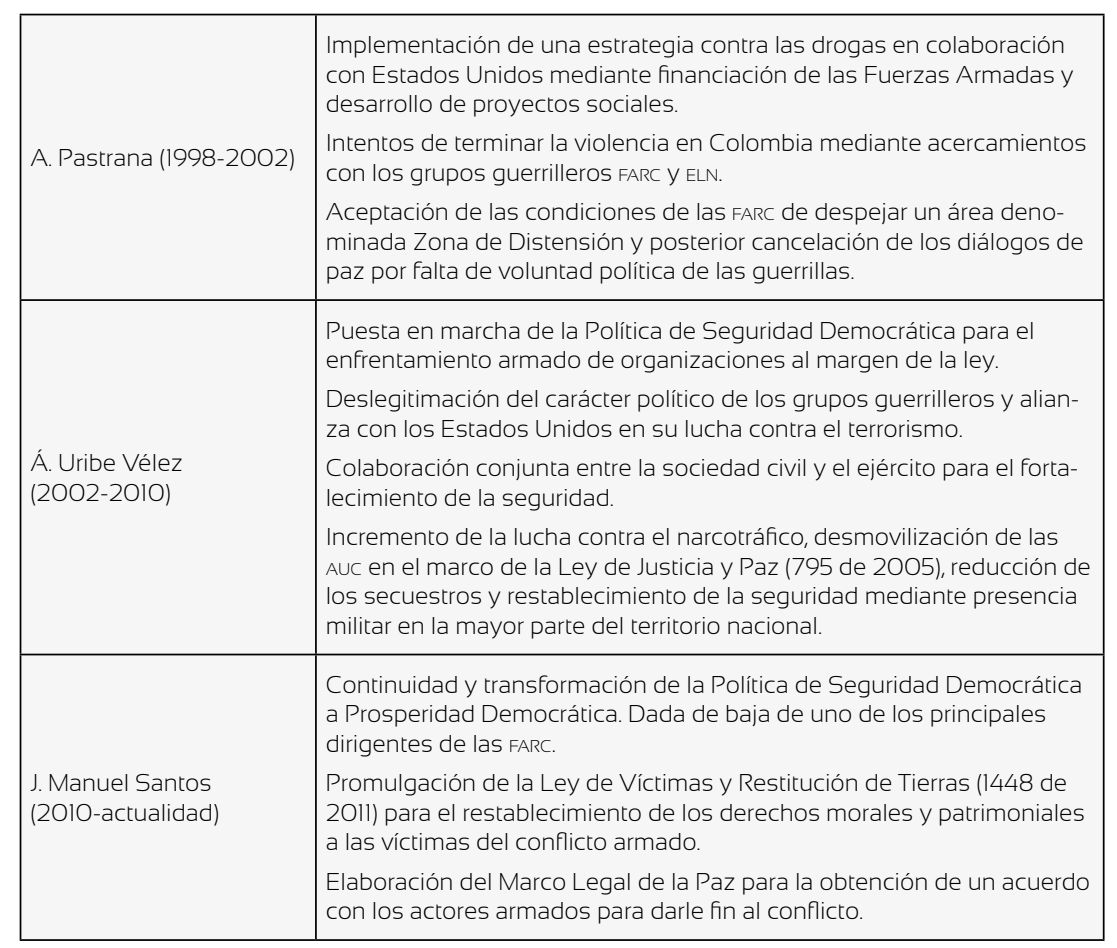

$\mathrm{Al}$ analizar esta narrativa desde las herramientas de indagación crítica, destaca la estructura del relato centrada en decisiones y acciones de los gobernantes dirigidas a garantizar el bienestar de la población, la seguridad y el orden público. La narrativa no se estructura alrededor de una problematización del conflicto armado y el uso de la violencia, pues el objetivo fundamental de los textos no es generar reflexión explícita sobre estas cuestiones, sino ofrecer un recuento de hechos destacados de la historia nacional reciente. Como se evidencia en la tabla anterior, tanto el conflicto como la violencia aparecen como fenómenos recurrentes de la realidad nacional. Sin embargo, los textos plantean pocas preguntas y explicaciones sobre las causas y transformaciones, las perspectivas de los diferentes actores, las consecuencias, los costos y daños causados, o las distintas interpretaciones posibles. De manera notoria, conflicto y violencia se tratan como un mismo fenómeno, sin explicar de manera diferenciada a qué se debe y cómo se transforma el conflicto, y por qué se desarrolla de manera violenta.

En los eventos y acciones que se incluyen en este relato se identifican dos secuencias narrativas desarticuladas entre sí. Por un lado, una secuencia que alterna el surgimiento y accionar de distintos grupos al margen de la ley y las correspondientes medidas de los gobiernos, bien 
sean de contención o para promover una paz negociada. Por otro lado, una secuencia de problemáticas sociales (desigualdad entre ricos y pobres, altos índices de pobreza, limitado acceso a recursos y oportunidades, entre otros), y las correspondientes reformas promovidas por los gobiernos para mejorar las condiciones de la población. Así, los hechos se organizan en forma de una secuencia simple que desmiembra la compleja red de factores causales que integra las dos secuencias. Más adelante veremos cómo esto se refleja en la explicación causal.

Por otra parte, encontramos una narrativa univocal, pues privilegia la perspectiva de uno solo de los actores, el Gobierno, que por demás es recurrentemente posicionado como un actor bien intencionado y comprometido con la seguridad, el bienestar y la paz de la sociedad colombiana. Cada gobierno en su momento toma las medidas necesarias para contener el ataque de los grupos armados, promoviendo iniciativas de negociación que en cada caso fracasan por razones ajenas a su voluntad. Otros actores (por ejemplo, guerrillas, paramilitares, narcotráfico) figuran en el relato solo en la medida en que guardan relación con la secuencia de acciones y reacciones de los gobiernos. De ellos se destacan sus acciones contra el Estado y la sociedad, así como su falta de voluntad para hacer realidad los acuerdos de paz promovidos por los gobiernos. Así, la representación de los actores es marcadamente dicotómica.

La selección de hechos y el lenguaje utilizado (acciones terroristas, secuestro o asesinato) hacen que en este relato se reconozca como violencia principalmente la que se deriva de las acciones de grupos al margen de la ley. Solo en unos pocos casos se señala la participación del Estado en la violación de los derechos humanos, y aunque esto se plantea explícitamente, se acompaña de cierta ambigüedad que desdibuja la posibilidad de reflexionar críticamente sobre la diferencia entre el monopolio y uso legítimo de la fuerza por parte del Estado, y el uso desmedido e ilegítimo de la violencia como herramienta política, movilizada por los intereses encontrados de distintos actores sociales. La siguiente cita ilustra esta ambigüedad:

La Política de Seguridad Democrática [gobierno de Álvaro Uribe] generó buenos resultados desde el año 2003: se incrementó la lucha contra el narcotráfico, se logró la desmovilización de las AUC en 2005, los secuestros se redujeron y se hizo presencia militar en la mayor parte del territorio [...]. Por otra parte, a medida que se daban los buenos resultados en materia de seguridad, se incrementaron los desplazamientos forzosos y las denuncias por violaciones a los derechos humanos. En 2008, la revelación de los falsos positivos puso en entredicho la eficacia de la seguridad democrática, pues como lo fueron demostrando diversas investigaciones, muchas personas que eran presentadas como guerrilleros muertos en combate, eran en realidad civiles asesinados por algunos miembros del Ejército (Santillana, 2013, p. 279). 
Finalmente, observamos que la estructura centrada en la acciones de los gobiernos restringe la visibilización de las consecuencias de la violencia y en particular la experiencia y el sufrimiento de las víctimas. En algunos puntos los textos plantean que las acciones de los grupos armados generan crisis institucional, estancamiento de la actividad económica y la productividad, desplazamiento de la población y pobreza. Pero estas referencias aparecen en frases dispersas y escuetas, lo que dificulta la comprensión de la magnitud del daño causado. En particular, está ausente la experiencia y perspectiva de las víctimas, como explicaremos con detalle.

\section{Estructura narrativa del jBasta Ya!}

En contraste con los textos escolares, la narrativa del ;Basta Ya! se estructura alrededor de la explicación del surgimiento y uso de la violencia por distintos actores en el contexto de los diversos conflictos sociales, resaltando también la experiencia humana de las víctimas. Según lo plantea el propio material, "El GMH fija como punto de partida de la narrativa del conflicto armado el esclarecimiento de las dimensiones de lo que pasó, cuándo y dónde ocurrió, cómo sucedió, quiénes lo hicieron y quiénes lo padecieron" (GMH, 2013, p. 31). Así, se da un panorama amplio de las distintas modalidades de la violencia en función de sus actores, explicando sus orígenes y transformaciones en el tiempo, y reconstruyendo los impactos, daños y memorias de aquellos que la padecieron. El Informe está divido en cinco capítulos, de los cuales se analizaron tres. En la tabla 4 se sintetizan los contenidos que vertebran la estructura de este relato.

Tabla 4. Contenidos del informe ¡Basta Ya!

\begin{tabular}{|l|l|}
\hline \multicolumn{1}{|c|}{ CAPITULO } & \multicolumn{1}{c|}{ CONTENIDO } \\
\hline $\begin{array}{l}\text { I. Dimensiones y } \\
\text { modalidades de } \\
\text { la guerra }\end{array}$ & $\begin{array}{l}\text { Trece modalidades de violencia (diferenciadas por actor). } \\
\text { Objetivos, repertorios y estadístzicas de cada una. } \\
\text { Lógicas del conflicto armado en Colombia y tratamiento de la población civil. }\end{array}$ \\
\hline $\begin{array}{l}\text { II. Orígenes y } \\
\text { transformaciones } \\
\text { de los grupos } \\
\text { armados }\end{array}$ & $\begin{array}{l}\text { Transformación de la violencia bipartidista en violencia subversiva (1958-1982). } \\
\text { Factores de la evolución del conflicto armado: Persistencia del problema agra- } \\
\text { rio, limitaciones y posibilidades de la acción política, irrupción del narcotráfico, } \\
\text { fragmentación institucional y territorial del Estado. } \\
\text { Resultados parciales y ambiguos de procesos de paz y reformas democráticas. } \\
\text { protesta social. } \\
\text { Surgimiento y expansión diferenciada de guerrillas y paramilitares, y luchas } \\
\text { por el territorio. } \\
\text { Políticas y diálogos de paz frustrados (FARC y ELN). } \\
\text { Negociación y desmovilización de las AUC, política de defensa y seguridad } \\
\text { democrática (2OO5-2Ol2), debilitamiento y reacomodo de las FARC e impacto } \\
\text { del rearme paramilitar. }\end{array}$ \\
\hline
\end{tabular}




\begin{tabular}{|l|l|}
\hline IV. Daños e & $\begin{array}{l}\text { Daño moral, sociocultural, victimación acentuada en afrocolombianos e indí- } \\
\text { genas y criminalización, persecución y represión a la sociedad civil. } \\
\text { impactos sobre } \\
\text { las víctimas }\end{array}$ \\
$\begin{array}{l}\text { Daños según modalidades de la violencia, impactos según género y edad. } \\
\text { Daños e impactos que ocasionan impunidad, deficiencias en atención estatal } \\
\text { yen respuestas sociales. }\end{array}$ \\
\hline
\end{tabular}

Fuente: Grupo de Memoria Histórica (2013).

El ¡Basta Ya! pone en el centro del relato el fenómeno de la violencia en la historia reciente de Colombia, y lo aborda como un problema que debe ser interrogado, explicado y comprendido con miras a prevenir su repetición. Esto supone un uso de la herramienta de planteamiento de problemas muy distinto, pues posiciona la barbarie y la degradación de la violencia como un objeto de reflexión, generando preguntas y explicaciones que cuestionan su normalización y legitimación. Como se refleja en la tabla 4, el surgimiento de la violencia se explica en el marco de condiciones de conflicto social, y se evidencia que la violencia no es un fenómeno natural e inevitable de las relaciones humanas, sino una construcción social e histórica, estrechamente vinculada con dinámicas sociales, intereses y estrategias particulares de distintos grupos sociales. Así mismo, se resalta la instrumentalización de la población civil, su impacto en las víctimas y en la sociedad en su conjunto, exponiendo los beneficios y los costos asociados a la violencia, y su distribución desigual.

Desde la misma estructuración del informe se plantea una aproximación sistémica que ahonda en las múltiples causas, manifestaciones y consecuencias de la guerra. El relato del iBasta Ya! entreteje el surgimiento y uso de la violencia por diversos actores en el contexto de múltiples conflictos sociales que atraviesan a la sociedad colombiana; se destacan la concentración de la propiedad agraria, la falta de pluralismo político y de posibilidades de los movimientos sociales, la fragmentación institucional y territorial del Estado, y la penetración del narcotráfico en las diversas esferas sociales, políticas y económicas.

Por otra parte, el ¡Basta Ya! presenta una narrativa a varias voces que describe la perspectiva de los distintos actores en su comprensión del conflicto, de los territorios y de la población civil, así como los intereses que ponen en juego al hacer uso de la violencia. A su vez, estas múltiples perspectivas son contrastadas con la experiencia de las víctimas. De esta manera se complejiza la comprensión de sus significados a la luz de las consecuencias que tienen para poblaciones específicas y para la sociedad en su conjunto.

El análisis diferenciado de las modalidades de violencia empleadas a lo largo y ancho del conflicto permite reconocer la violencia ejercida tanto por las guerrillas y los paramilitares como por las Fuerzas Armadas, en la medida en que violan los derechos humanos y contribuyen al recrudecimiento del conflicto. 
La violencia de los miembros de la Fuerza Pública se centró en las detenciones arbitrarias, las torturas, los asesinatos selectivos y las desapariciones forzadas, así como en los daños colaterales producto de los bombardeos, y del uso desmedido y desproporcionado de la fuerza (GMH, 2013).

Así, se analiza la lucha de las fuerzas del Estado por recuperar el monopolio de la fuerza en las regiones, pero sin pasar por alto cuándo estas sobrepasan los marcos legales y los principios democráticos, así como las condiciones y factores que hacen esto posible. Por otra parte, la narrativa reconoce como violencia tanto sus formas directas (modalidades de la violencia en el conflicto armado) como la violencia estructural de las distintas formas de desigualdad y exclusión social que interactúan con la violencia directa.

Es notorio el énfasis de esta narrativa en las consecuencias de la violencia y la experiencia de las víctimas. Describe los efectos de la violencia en distintos niveles económicos y políticos, al tiempo que documenta con especial atención sus impactos en las víctimas (huella emocional, daños morales y socioculturales). Este análisis diferencia los efectos de cada modalidad de violencia, considerando el género y la edad de las víctimas. El énfasis en consecuencias y daños invita a la reflexión sobre las posibilidades y la necesidad de alcanzar los objetivos de distintos actores mediante otros mecanismos no violentos.

Tabla 5. Contraste de la estructura narrativa de textos escolares y iBasta Ya!

\begin{tabular}{l|l}
\multicolumn{1}{c|}{ Textos escolares } & \multicolumn{1}{c}{ iBasta Ya! } \\
\hline $\begin{array}{l}\text { Centrada en decisiones y acciones } \\
\text { de los gobiernos }\end{array}$ & Centrada en la violencia como problema \\
\hline Secuencias cronológicas lineales desarticuladas & Red de factores causales entretejidos \\
\hline $\begin{array}{l}\text { Narrativa univocal: privilegia perspectiva } \\
\text { del Estado }\end{array}$ & $\begin{array}{l}\text { Narrativa multivocal: integra la perspectiva de } \\
\text { distintos actores }\end{array}$ \\
\hline $\begin{array}{l}\text { Cuestiona especialmente la violencia de actores } \\
\text { al margen de la ley }\end{array}$ & $\begin{array}{l}\text { Cuestiona tanto la violencia de actores ilegales } \\
\text { como el uso desmedido de la fuerza por parte } \\
\text { del Estado }\end{array}$ \\
\hline $\begin{array}{l}\text { Poca referencia a las consecuencias de la } \\
\text { violencia y experiencia de las víctimas }\end{array}$ & $\begin{array}{l}\text { Centralidad de las consecuencias de la violencia } \\
\text { la perspectiva de las víctimas }\end{array}$ \\
\hline
\end{tabular}

\section{Explicación de las causas del conflicto y la violencia en los textos escolares}

La herramienta del pensamiento sistémico resalta que la comprensión crítica de los fenómenos sociales descansa en parte en la explicación multicausal de los orígenes y transformaciones de los mismos, evidenciando 
los sistemas sociales y los procesos históricos en los que se insertan los hechos particulares. Por otra parte, la explicación sistémica supone también la articulación de las acciones e intenciones de los sujetos individuales y colectivos con el entramado de factores causales que interactúan como motores tanto del cambio como de la continuidad en los fenómenos sociales e históricos.

En contraste con este criterio, los textos escolares ofrecen una explicación unicausal del origen de los grupos guerrilleros. La explicación se remonta a la exclusión política durante el Frente Nacional, que generó distintas formas de oposición, entre las que se encuentra la lucha armada: "Dicho pacto [Frente Nacional] puso fin a la violencia entre partidos, pero dio paso a la exclusión de otras tendencias políticas, lo cual generó una nueva etapa de la violencia durante la cual surgieron grupos guerrilleros" (Santillana, 2012, p. 256). De esta forma, la conformación de las guerrillas se explica como la opción de estos grupos por la vía de la violencia, como estrategia revolucionaria para promover el levantamiento de las masas y el derrocamiento del régimen excluyente, en lugar de optar por otras vías políticas:

La oposición al Frente Nacional se puede dividir en tres grupos: los sectores disidentes de los partidos políticos tradicionales, la Alianza Nacional Popular, Anapo, y los partidos de izquierda. A la vez este último grupo se dividió en dos sectores: uno dedicado a la lucha armada y otro a la lucha política (Santillana, 2012, p. 260).

Poco o nada se dice en los textos sobre el problema agrario que sienta las bases del conflicto más profundo e influye en las opciones políticas de los grupos guerrilleros y otros movimientos sociales de la época.

De ahí en adelante la violencia aparece intermitentemente, a medida que la narrativa va relatando el surgimiento de nuevos actores, la intensificación en las acciones armadas por parte de los distintos grupos ilegales, las confrontaciones entre ellos o con el Estado, y las respuestas de los sucesivos gobiernos para la defensa y el control del orden público. De esta manera, la evolución del conflicto armado se explica a partir de la secuencia de eventos y acciones entre los que prima una relación simple de acción y reacción. Esta explicación lineal no ayuda a comprender las coyunturas en las que eclosionan diversos factores, que generan experiencias, necesidades, intereses y lógicas que subyacen a las prácticas de los distintos actores y a las complejas relaciones que se dan entre ellos. Por ejemplo, respecto al surgimiento y actuación de los grupos guerrilleros simplemente se dice:

Durante el Frente Nacional, e influidos por la Revolución Cubana, muchos izquierdistas consideraron que en el país existían las condiciones para una revolución. Por tanto impulsaron la formación de grupos guerrilleros en las zonas rurales, como las Fuerzas Armadas Revolucionarias

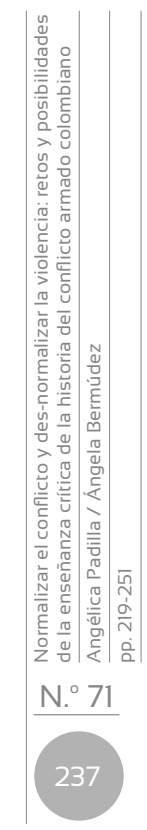


de Colombia (FARC), el Ejército de Liberación Nacional (ELN) y el Ejército Popular de Liberación (EPL) (SM, 2012, p. 209).

Los grupos guerrilleros, que abarcan a guerrillas de izquierda como el ELN y las FARC, se financian con acciones delictivas como el secuestro, la extorsión, y la producción y comercialización de narcóticos. Luchan por mantener el control sobre sus zonas de influencia y corredores estratégicos (SM, 2012, p. 215).

Aunque los textos escolares mencionan distintos aspectos de carácter sistémico, como la pobreza y la desigualdad social, estos no se articulan en una explicación causal que permita entender las bases estructurales del conflicto y cómo estas contribuyen a generar la violencia. "En el plano económico, Barco intentó disminuir la pobreza en las regiones más golpeadas por la violencia, mediante la aplicación del Plan Nacional de Rehabilitación, PNR. Además, promovió una mayor presencia del Estado en zonas marginales y de orden público crítico" (Santillana, 2013, p. 265). En este ejemplo Ilama la atención que las reformas y programas sociales se describen como medidas para hacer frente o paliar la pobreza en las regiones de mayor violencia, pero no es claro si dicha pobreza es consecuencia de la violencia o la base material que la genera. En los sucesivos gobiernos se implementan planes de reforma social con objetivos similares pero no se analiza su alcance y efectividad. De esta manera, la secuencia de acciones y reacciones no permite entender la continuidad y la transformación en las bases estructurales del conflicto.

Respecto al surgimiento de los grupos paramilitares en los años ochenta, uno de los textos plantea simplemente que estos nacen en respuesta al actuar de las guerrillas. A partir de allí, sigue relatando la consolidación y el actuar de estos grupos:

Por su parte, en 1997, los grupos paramilitares se unificaron y se Ilamaron Autodefensas Unidas de Colombia, bajo la dirección de Carlos Castaño y Salvatore Mancuso. Este grupo disputó a la guerrilla zonas estratégicas para el control de rutas del narcotráfico y con grandes recursos naturales (SM, 2012, p. 222).

Más adelante y luego de la desmovilización de los paramilitares, se describe el surgimiento de bandas criminales como grupos aislados reductos del paramilitarismo: "Entre 2003 y 2006, se presentó la desmovilización de las Auc en varias zonas del país. Sin embargo, algunos reductos continuaron sus actividades delictivas y pasaron a Ilamarse Bandas Emergentes Criminales o Bacrim" (SM, 2012, p. 222).

En este punto es interesante anotar una diferencia importante del texto anterior con los otros dos, por cuanto aquellos mencionan distintos momentos en que estos grupos armados se formaron o fortalecieron al amparo de la ley. Por ejemplo uno de los textos señala que, 
Durante la década de los noventa, los grupos paramilitares tuvieron un crecimiento considerable, muchas veces auspiciados por terratenientes e incluso por algunos políticos y miembros de las fuerzas oficiales. A finales del gobierno Gaviria, el paramilitarismo volvió a tener un impulso institucional con la promulgación del Decreto 356 de 1994 que creó las Cooperativas de Vigilancia y Seguridad Privada para la autodefensa agraria (Convivir), que fueron patrocinadas desde 1995 por el entonces gobernador de Antioquia, Álvaro Uribe Vélez (Santillana, 2013, p. 276).

Así mismo, los textos hacen referencia a los casos en que los paramilitares cuentan con el apoyo de distintas fuerzas del Estado por fuera de los marcos legales:

En el mismo año en que Uribe comenzó su segundo mandato, se destapó la parapolítica, el primer gran escándalo de su gobierno, en el que un buen número de senadores cercanos a su proyecto político [...] fueron acusados de tener relaciones con jefes paramilitares (Santillana, 2013, p. 279).

Indudablemente es importante la mención explícita a la responsabilidad del Estado en el actuar y fortalecimiento de los paramilitares; sin embargo, con una mención tan escueta de un fenómeno tan complejo es difícil entender sus causas y las implicaciones para el desarrollo del conflicto y de la vida política del país.

\section{Explicación de las causas del conflicto y la violencia en el ¡Basta Ya!}

En el ¡Basta Ya! encontramos una explicación multicausal de la violencia, que se sitúa en procesos históricos de mediano plazo. El conflicto armado colombiano se describe como un proceso que ha sido heterogéneo en el tiempo y el territorio, debido a la persistencia del problema agrario, las limitaciones y posibilidades de la participación política, las influencias y presiones del contexto internacional, la irrupción y propagación del narcotráfico, la fragmentación institucional y territorial del Estado y el limitado alcance de sus reformas.

La narrativa del ;Basta Ya! hace conexiones explicativas explícitas entre problemáticas sociales, la transformación del conflicto y el surgimiento de la violencia. Por una parte, la explicación incluye una descripción amplia de las condiciones sociales que propiciaron estrategias de oposición violentas:

La crisis agraria de aquel entonces [1960], al igual que hoy, quedaba evidenciada en la extrema desigualdad de la distribución de la tierra y en la aguda pobreza de la población rural. [...] El reducido alcance de las reformas sociales y económicas, y el escenario de represión militar y de restricción política del Frente Nacional, sirvieron de caldo de cultivo de la vía armada y de la radicalización de algunos sectores políticos de la izquierda (GMH, 2013, p. 120).

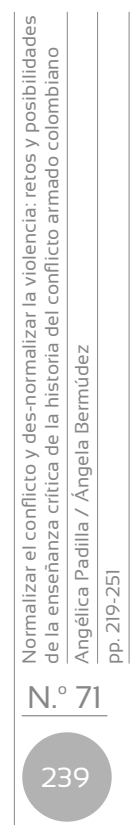


La metáfora del "caldo de cultivo" sirve para explicar cómo se generan escenarios favorables a la lucha armada. De otro lado, se explica cómo el entramado estructural facilita el uso premeditado de la violencia como herramienta estratégica, a través de la cual los distintos grupos armados promueven sus intereses sociales, políticos y económicos.

Es preciso reconocer que la violencia que ha padecido Colombia durante muchas décadas no es simplemente una suma de hechos, víctimas o actores armados. La violencia es producto de acciones intencionales que se inscriben mayoritariamente en estrategias políticas y militares, y se asientan sobre complejas alianzas y dinámicas sociales. Desde esta forma de comprender el conflicto se pueden identificar diferentes responsabilidades políticas y sociales frente a lo que ha pasado (GMH, 2013, p. 31).

La violencia que se presenta en el ;Basta Ya! es deliberada y planificada, en la medida en que es un instrumento en la disputa por territorios estratégicos para el narcotráfico, la lucha por el acceso a recursos naturales y fuentes de riqueza o la reconfiguración de la propiedad de la tierra. Las distintas modalidades de violencia de cada grupo se relacionan directamente con estos objetivos instrumentales. El análisis diferenciado de las distintas modalidades de violencia, aunque pueda parecer crudo, permite visibilizar este carácter de herramienta estratégica:

Todos han desplegado diversas modalidades y cometido crímenes de guerra y de lesa humanidad, haciendo a la población civil la principal víctima del conflicto [...]. En términos de repertorios de violencia, los paramilitares ejecutaron en mayor medida masacres, asesinatos selectivos y desapariciones forzadas, e hicieron de la sevicia una práctica recurrente con el objeto de incrementar su potencial de intimidación. Las guerrillas, por su parte han recurrido primordialmente a los secuestros, los asesinatos selectivos, y los atentados terroristas, además del reclutamiento forzado y el ataque a bienes civiles. Con respecto a la violencia ilegal de miembros de la Fuerza Pública, se ha podido establecer con base en testimonios y en sentencias judiciales el empleo de modalidades como las detenciones arbitrarias, las torturas, los asesinatos selectivos y las desapariciones forzadas (GMH, 2013, p. 20).

Tabla 6. Contraste explicación causal de la violencia en textos escolares y ¡Basta Ya!

\begin{tabular}{l|l}
\hline \multicolumn{1}{c|}{ Textos escolares } & \multicolumn{1}{c}{ ¡Basta Ya! } \\
\hline \multicolumn{1}{c}{ Explicación unicausal } & \multicolumn{1}{c}{ Explicación multicausal } \\
\hline $\begin{array}{l}\text { Secuencia desarticulada de acciones de grupos } \\
\text { armados/respuestas del Gobierno y problemas } \\
\text { sociales/reformas promovidas por el Gobierno }\end{array}$ & $\begin{array}{l}\text { Continuidad de condiciones sociales y limita- } \\
\text { ción de las reformas promovidas por el gobierno } \\
\text { como caldo de cultivo de la violencia }\end{array}$ \\
\hline $\begin{array}{l}\text { Violencia como opción de los actores al } \\
\text { margen de la ley frente a exclusión política } \\
\text { por parte del Gobierno }\end{array}$ & $\begin{array}{l}\text { Explicación del uso de la violencia como } \\
\text { herramienta estratégica por parte de todos los } \\
\text { actores involucrados en el conflicto }\end{array}$ \\
\hline
\end{tabular}




\section{La representación de las víctimas en los textos escolares}

La explicación crítica de los conflictos y la violencia descansa también sobre la comprensión de las perspectivas de los diversos actores involucrados. Esto supone no solo identificar a los actores relevantes y sus posiciones, sino sobre todo, reconstruir sus perspectivas en los contextos sociales e históricos en los que cobran sentido. Ante situaciones de conflicto y vulneración, es particularmente importante comprender la experiencia de los actores, incluyendo por ejemplo sus dilemas y controversias, o lo que ganan y pierden en los conflictos. En esta línea, los enfoques que integran la enseñanza de la historia y la educación para la paz resaltan la urgencia de dar voz a las víctimas del conflicto y a su experiencia de vulneración.

Considerando este criterio, Ilama la atención la poca presencia que tienen las víctimas de la violencia en los relatos sobre el conflicto armado en los textos escolares. La representación de su experiencia es excesivamente general y aséptica, y en ningún caso se les da voz para, a través de sus testimonios, dar cuenta del daño emocional, físico, social, cultural y económico en la población civil. En los textos escolares hay una descripción tímida de la violencia, de la magnitud del daño y del detalle de las acciones perpetradas por los distintos actores. La cuestión no es que no se mencionen los impactos de la violencia en la sociedad civil. Los tres textos lo hacen, utilizando además un lenguaje que señala la crueldad y la destrucción que esta genera. Por ejemplo, en los textos encontramos descripciones como las siguientes:

[Después de describir las acciones violentas ejercidas por los distintos actores armados] el sector más perjudicado por sus acciones ha sido la sociedad civil. Grupos armados de derecha e izquierda realizan actividades ilegales, como la extorsión y el secuestro, para financiarse y controlar las actividades delictivas en las ciudades. Los efectos del conflicto son cuantiosos e incalculables no solo en términos materiales sino y más grave aún, por la destrucción del tejido social de regiones enteras (sM, 2012, p. 222).

La guerra contra las drogas [Plan Colombia] ha generado desplazamiento forzado y masivo de campesinos e indígenas a las principales ciudades del país, quienes amenazados por guerrilleros y paramilitares son despojados de sus casas y tierras, no teniendo más opciones que desplazarse hacia otros lugares, donde generalmente deben empezar una nueva vida [...]. Debido a su presencia [Auc] en el conflicto armado, la violencia se exacerbó, pues los métodos utilizados por estos grupos Ilegaron a extremos impensables de violación de los derechos humanos (Norma, 2011, pp. 192,193).

Lo que estos fragmentos muestran es que aun cuando los textos mencionan fenómenos de victimación, como la violación de los derechos 
humanos, el desplazamiento, la extorsión y el secuestro, la descripción se hace a tal nivel de generalidad que no lleva al lector a dimensionar los costos que se derivan del uso de la violencia como estrategia política y militar de dominación del territorio. Estas menciones tan escuetas no generan una comprensión más profunda de cuáles derechos fueron vulnerados, de qué forma y la impronta en la sociedad y los imaginarios colectivos. Expresiones como "efectos cuantiosos e incalculables" o "métodos que llegaron a extremos impensables de violación de los derechos humanos" denotan la gravedad de la situación, pero no acercan al lector a la textura de la experiencia humana desde la cual pueda empatizar con las víctimas de la violencia y comprender la magnitud del daño causado. Visto desde esta perspectiva, la noción de que aquellos que fueron despojados de sus casas y tierras y obligados a desplazarse a otros lugares, "empiezan una nueva vida" no refleja con suficiente claridad o fuerza el drama de las pérdidas, el desarraigo y los traumas irreparables, ni los retos y el coraje de los que logran reiniciar una vida o retornar. Por otra parte, al no diferenciar la experiencia de distintos grupos poblacionales, se pierden los matices y la diversidad de formas en que la violencia contra la población civil se constituye en un arma de guerra. Los textos no incluyen referencias por ejemplo al terror, la humillación o la intimidación, generado en las comunidades por la invasión de grupos armados, la frustración por lesiones físicas, el proyecto de vida truncado por el reclutamiento ilícito o el trauma causado por la violencia sexual, entre otros.

\section{La representación de las víctimas en el ¡Basta Ya!}

En contraste con los textos escolares, el jBasta Ya! sitúa la memoria de las víctimas de la violencia en el centro del relato. Así se acentúa la dimensión humana del conflicto, y sus perspectivas interpelan a los distintos actores armados responsables de la vulneración de los derechos humanos, sean estos grupos de derecha, de izquierda o de las fuerzas del Estado.

La historia del conflicto se relata desde la voz de hombres y mujeres que padecieron la violencia deliberada de los distintos actores enfrentados. Sus testimonios ponen en evidencia la huella emocional, el daño moral y la devastación sociocultural que genera la guerra, resaltando la complejidad y diversidad de las experiencias de victimación, que van mucho más allá de los daños materiales y económicos:

A la comunidad Wayuu nos destruyeron moral y culturalmente. La historia de los Wayuu y los guajiros cambió, porque bajaron la cabeza cuando entró el paramilitarismo. Y no hay venganza ni guerra. Los paramilitares venían con el pensamiento claro: análisis del terror. A los hombres: varios tiros. A las mujeres: decapitadas, cortadas de senos [...]. Humillación a la mujer y a los hombres. Están marcados. Con todo lo que hicieron, nos hirieron tanto que supieron herirnos como 
comunidad y como personas con todo lo que consideramos como sagrado (GMH, 2013, p. 270).

Los testimonios de las víctimas ilustran las distintas modalidades de violencia que cada uno de los actores del conflicto ha empleado contra la población civil. Estas descripciones permiten entender el porqué del repertorio de violencia (las razones instrumentales), diferenciado por actores armados. Pero también muestra cómo distintos grupos de la población colombiana vivieron esas experiencias y lo que han representado para sus vidas:

Salí con mis siete hijos y cargaba otro en la barriga... A mi esposo lo mataron delante de nosotros. Salí sin mi esposo, sin tierra, sin ropa, sin dinero, ¡sin nada!... Sola, con la cantidad de niños. Llegué a Montería a buscar cómo mantener estos niños, no podía dejarlos morir de hambre. No había tiempo para la tristeza, no había tiempo para nada. Tenía que buscar dónde dormir, qué hacer para darles un pan y una aguadepanela a los niños (GMH, 2013, p. 306).

Yo vivo muriéndome — nos dijo un agricultor de cincuenta años de edad, quien perdió una pierna y casi toda la visión cuando pisó una mina antipersonal cuatro años antes-. Ahora vivo de limosnas y [de] los hijos que le dan comida a uno. Vivo con los tres menores [...] Tengo tres años de [estar así] y no me muero (GMH, 2013, p. 95).

Finalmente, el ¡Basta Ya! resalta también el impacto desigual de la violencia que afecta desproporcionadamente a algunos sectores de la población:

Nadie ha estado exento de la guerra, es verdad, pero los informes y los datos que registran las violaciones a los Derechos Humanos constatan que la guerra no ha afectado a todos por igual. La guerra recae especialmente sobre las poblaciones empobrecidas, sobre los pueblos afrocolombianos e indígenas, se ensaña contra los opositores y disidentes, y afecta de manera particular a las mujeres, a los niños y niñas (GMH, 2013, p. 25).

Tabla 7. Contraste representación de las víctimas en textos escolares y ¡Basta Ya!

\begin{tabular}{l|l}
\multicolumn{1}{c|}{ Textos escolares } & \multicolumn{1}{c}{ ¡Basta Ya! } \\
\hline $\begin{array}{l}\text { Poca presencia de víctimas y su perspectiva en } \\
\text { el relato. }\end{array}$ & Victimas y su perspectiva en el centro del relato. \\
\hline $\begin{array}{l}\text { Experiencia de las víctimas representada de } \\
\text { manera general y aséptica. }\end{array}$ & $\begin{array}{l}\text { Descripción detallada y testimonios de la expe- } \\
\text { riencia de vulneración. }\end{array}$ \\
\hline $\begin{array}{l}\text { Representación limitada de las distintas formas } \\
\text { de violencia contra la población civil. }\end{array}$ & $\begin{array}{l}\text { Ilustración de repertorio de } 13 \text { modalidades de } \\
\text { violencia, diferenciadas por actor, y consecuen- } \\
\text { cias para la población. }\end{array}$ \\
\hline $\begin{array}{l}\text { Señala las consecuencias generales de violen- } \\
\text { cia para la sociedad. }\end{array}$ & $\begin{array}{l}\text { Destaca el impacto diferenciado de la violencia } \\
\text { en distintos grupos poblacionales. }\end{array}$ \\
\hline
\end{tabular}




\section{Discusión y conclusiones}

En este artículo hemos contrastado dos formas de narrar la historia del conflicto armado colombiano. El análisis de datos arroja un contraste tajante entre los relatos que presentan los textos escolares y el informe ¡Basta Ya!, tanto en (1) la estructura narrativa, como en (2) la explicación de las causas de la violencia y (3) la representación de la experiencia de las víctimas.

La conclusión fundamental es que el relato sobre el conflicto armado común a los textos escolares tiene serias carencias que limitan su contribución como recurso educativo en el contexto de un proceso de construcción de paz. El análisis busca evidenciar que la estructura estrictamente cronológica y el enfoque temático presidencialista no favorece la comprensión crítica del conflicto y la deslegitimación de la violencia. Dentro de ello hemos destacado cómo: (1) privilegia la perspectiva del Estado, lo que dificulta la comprensión de las perspectivas, objetivos e intereses de los distintos actores enfrentados en el conflicto; b) desmiembra la red de factores causales que explican el origen y la transformación del conflicto, lo que dificulta la comprensión de su prolongación y degradación; y c) margina la experiencia y la voz de las víctimas, lo que dificulta comprender la magnitud del daño emocional, físico, social, cultural y económico en la población civil. El relato ofrecido por el ¡Basta Ya!, por el contrario, muestra fortalezas que sugieren el potencial pedagógico de las narrativas que buscan explicar los conflictos en su complejidad, y Ilaman la atención sobre las tragedias que estos dejan cuando se tramitan por la vía de la violencia.

Es indudable que el contraste entre estos relatos, desde su diseño metodológico, plantea un desequilibrio que puede resultar inquietante. Dada la intención y perspectiva del Grupo de Memoria Histórica, no sorprende que el informe iBasta Ya! busque expresamente explicar las distintas causas de la guerra y su transformación en el tiempo, dar cuenta de la magnitud y degradación del uso de la violencia política, y resaltar sus consecuencias e impactos sobre la población civil. La experticia de sus autores y la extensión del informe permiten abordar estas cuestiones con mayor detalle, profundidad y riqueza de matices; y su carácter investigativo y no comercial hace posible presentar perspectivas críticas con mayor libertad.

Por su parte, la estructura, el estilo y el enfoque de los textos escolares no refleja necesariamente la perspectiva de sus autores, dado que están fuertemente pautados por los currículos oficiales, por la expectativa de cubrir muchos contenidos en un espacio reducido y por criterios comerciales que buscan garantizar su éxito entre docentes y estudiantes. El conflicto armado es solo uno de los varios temas que deben abordar los textos. Estos 
términos restringen considerablemente las posibilidades de profundización y tratamiento reflexivo de problemas cruciales en la actualidad.

Dicho contraste no significa que el ;Basta Ya! no tenga carencias, y reconocemos que la delimitación de nuestro análisis no permite visibilizar sus posibles limitaciones. En la discusión pública del mismo se ha cuestionado, por ejemplo, la periodización del conflicto armado a partir del año 1958, entre otras cosas porque deja por fuera un número importante de actores y de víctimas de la violencia política en Colombia durante el siglo xx. Una visión más amplia sería sin duda más provechosa para la comprensión que alcancen los estudiantes. Se ha cuestionado también el hecho de que los miembros del equipo de investigadores provinieran en su mayoría de enfoques historiográficos cercanos a la izquierda, lo que restringe la inclusión de otras perspectivas en la reconstrucción de la memoria histórica. En un análisis más amplio de este material y de sus usos educativos, valdría la pena considerar las limitaciones que este sesgo pueda generar a la hora de ayudar a los estudiantes a comprender el carácter interpretativo del conocimiento histórico, y los retos profundamente complejos de coordinar narrativas contrapuestas. Aun así, debemos anotar que esta crítica se ha visto asociada con frecuencia al hecho de que el informe cuestiona a la par la violencia de los movimientos guerrilleros y paramilitares y el uso desmedido de la fuerza por parte de organismos del Estado. Desde nuestra perspectiva, dicho cuestionamiento de la violencia independientemente de su autoría y de la identidad de sus víctimas es un imperativo ético ineludible si se quiere construir una comprensión crítica de la violencia que contribuya a cimentar una cultura de paz sostenible.

No podemos pasar por alto otro cuestionamiento que se hace del ¡Basta Ya! como una nueva "versión oficial" de la historia del conflicto armado, que excluye o margina versiones alternativas. Planteada fundamentalmente desde la izquierda, esta crítica se deriva del hecho de que el GMH y el CNMH fueran fundados y parcialmente financiados en el marco de las políticas de paz del Estado. Sin embargo, a la luz del análisis que presentamos aquí, Ilama la atención el contraste con lo que también podría considerarse la "versión oficial" de la historia del conflicto armado que presentan los textos escolares. En este sentido, el contraste tajante pone en evidencia la complejidad de los procesos a través de los cuales los relatos "oficiales" y "alternativos" se configuran y reconfiguran. A pesar de sus limitaciones, este nuevo "relato oficial" muestra un potencial importante para ampliar, profundizar y complejizar la comprensión de los ciudadanos del común.

Por otra parte, queremos señalar que el contraste entre los textos y el ¡Basta Ya!, aunque particular en sus contenidos específicos, refleja patrones comunes encontrados en el análisis de los relatos sobre los otros hechos históricos en los tres países incluidos en el estudio en el que se

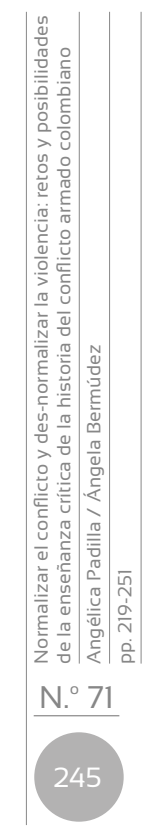


enmarca este artículo. En el transcurso del análisis comparado se identificaron diez claves narrativas que definen la forma en que los relatos históricos representan la violencia política. El patrón recurrente sugiere que los textos escolares tienden a normalizar o invisibilizar la violencia, mientras que los materiales alternativos que abordan el pasado violento de manera explicita y reflexiva tienden a desnormalizar la violencia y a fomentar la comprensión crítica de la misma (Bermúdez, 2016).

La eventual firma de los acuerdos en La Habana puede generar un contexto favorable para repensar la enseñanza de la historia en relación con la educación para la paz. La Ley 1732 de 2014 estableció la Cátedra de la Paz en todas las instituciones educativas, con el fin de garantizar la creación y el fortalecimiento de una cultura de paz. Hay opiniones encontradas al respecto; muchos piensan que una asignatura más solo incrementa el volumen de trabajo de los docentes sin resolver los problemas de fondo. Otros opinan que le garantiza un tiempo en el calendario escolar. Consideramos que esta cátedra puede constituirse en un espacio de diálogo y reflexión necesario, por ejemplo, a la luz de lo que hemos planteado en este artículo. Sin embargo, vemos que es fundamental no solo abrir nuevos espacios, sino transformar aquellos que actualmente existen. La enseñanza de la historia debe ofrecer posibilidades de entender críticamente el presente y preparar a las nuevas generaciones para afrontar el gran reto de construir una cultura de paz en una sociedad permeada por la violencia.

Indudablemente, los retos y posibilidades de una aproximación crítica a la historia del conflicto armado serán muy distintos en distintas escuelas. Lizarralde (2012) pone de manifiesto cómo se ha normalizado la violencia en los ambientes educativos en regiones del país donde es más álgido el conflicto armado. Plantea que el miedo condiciona la mayoría de las interacciones en las escuelas y genera actitudes que normalizan la violencia como mecanismo de protección. Aun así, destaca experiencias de comunidades educativas donde las redes de apoyo solidarias han permitido desarrollar propuestas pedagógicas que apuntan a la transformación de los imaginarios violentos de la guerra. Consideramos que las narrativas desde las que se enseña la historia del conflicto armado pueden apoyar esa transformación. Aun así, es necesario contar con más investigación sobre la experiencia de los maestros al enseñar estos temas (Ávila, 2012), y sobre todo, al intentar hacerlo de manera crítica y reflexiva. Esto es parte de la segunda fase de nuestra investigación, en la que hemos explorado los retos y oportunidades que enfrentan docentes comprometidos con una educación transformadora en distintos colegios en Bogotá y el Magdalena Medio. 


\section{Referencias bibliográficas}

Acevedo, A. \& Samacá, G. (2012). La política educativa para la enseñanza de la historia de Colombia (1948-1990): de los planes de estudio por asignaturas a la integración de las ciencias sociales. Revista Colombiana de Educación, 62, 221-244.

Andrews, M. (2007). Shaping history: Narratives of political change. Nueva York: Cambridge University Press.

Ávila, S. (2012). Formación de maestros para el presente: Memoria y enseñanza de la historia reciente. Revista Colombiana de Educación, 62, 165-188.

Bajaj, M. (2008). 'Critical' peace education. M. Bajaj (Ed.), Encyclopedia of peace education (pp. 135-146). Charlotte, North Carolina: Information Age.

Barber, B. (2009). Adolescents and war: How youth deal with political violence. Nueva York: Oxford University Press.

Bar-Tal, D. (2000). Shared beliefs in a society: Social psychological analysis. Thousand Oaks, California: Sage.

Barton, K. \& Levstik, L. (2004). Teaching history for the common good. New Jersey: Routledge.

Barton, K. \& McCully, A. (2005). History, identity, and the school currículum in Northern Ireland: An empirical study of secondary students' ideas and perspectives. Journal of Currículum Studies, 37(1), 85-116. doi:10.1080/0022027032000266070

Barton, K. \& McCully, A. (2007). Teaching controversial issues... where controversial issues really matter. Teaching History, 127, 13-19.

Bastida, A. (1994). Educar para la paz a través de la guerra. Cuadernos de Pedagogía, 227, 97-100.

Bastida, A.; Lugo, S. \& Rocasalbas, M. (2008). El conflicto armado en el aula: dos experiencias. Enseñanza de las Ciencias Sociales: Revista De Investigación 7, 141-149.

Bekerman, Z. \& Zembylas, M. (2012). Teaching contested narratives: Identity, memory and reconciliation in peace education and beyond. Nueva York: Cambridge University Press.

Bermúdez, A. (2012). The discursive negotiation of cultural narratives and social identities in learning history. History Teaching and National Identities. International Review of History Education, 5, 203-219.

Bermúdez, A. (2015). Four tools for critical inquiry in history, social studies, and civic education. Revista de Estudios Sociales, 52, 102-118. doi:http://dx.doi.org/10.7440/res52.2015.07

Bermúdez, A. (2016). Ten narrative keys to normalize or de-normalize political violence in history textbooks. Internal research report. [Inédito]. 
Bruner, J. (1990). Acts of meaning: Four lectures on mind and culture. London: Cambridge, MA: Harvard University Press.

Bruner, J. (1991). The narrative construction of reality. Critical Inquiry, 18, $1-21$.

Carretero, M. (2011). Constructing patriotism: Teaching history and memories in global worlds. Charlotte, North Carolina: Information Age.

Carretero, M.; Asensio, M. \& Moneo, M. R. (2012). History education and the construction of national identities. Charlotte, North Carolina: Information Age.

Carretero, M.; Haste, H. \& Bermúdez, A. (2016). Civic education. In L. Corno \& E. M. Anderman (eds.), Handbook of Educational Psychology (3 ${ }^{\text {rd. }}$ ed., pp. 295-308). Nueva York: Routledge.

Clark, P. (2006, otoño). Images of aboriginal people in British Columbia Canadian history textbooks. Canadian Issues, 47-51.

Cole, E. (2007). Reconciliation and history education. En E. Cole (ed.). Teaching the violent past: History education and reconciliation (pp. 1-28). Maryland: Rowman \& Littlefield.

Dickinson, P. Lee \& Rogers, P. (Eds.). Learning history. London: Heinemann Educational Publishers.

Epstein, T. (2009). Interpreting national history: Race, identity, and pedagogy in classrooms and communities. Nueva York: Routledge.

Etxeberria, X. (2013). La educación para la paz reconfigurada: la perspectiva de las víctimas [prefacio de Victoria Camps Cervera]. Madrid: Catarata.

Ferro, M. (1984). The use and abuse of history: Or how the past is taught to children. Nueva York: Routledge.

Galtung, J. (1996). Paz por medios pacíficos: Paz y conflicto, desarrollo y civilización (T. Toda, trad.). Bilbao: Gernika Gogoratuz-Bakeaz.

Galtung, J. (1998). Tras la violencia, 3R: Reconstrucción, reconciliación y resolución. Afrontando los efectos visibles e invisibles de la guerra y la violencia. (T. Toda, trad.). Bilbao: Gernika Gogoratuz-Bakeaz.

Garrett, H. J. (2011). The routing and re-routing of difficult knowledge: Social studies teachers encounter when the levees broke. Theory \& Research in Social Education, 39 (3), 320-347.

Grupo de Memoria Histórica. (2013). ¡Basta Ya! Colombia: memorias de guerra y dignidad. Bogotá: Centro Nacional de Memoria Histórica.

Gómez, D. (2015). La enseñanza de las ciencias sociales en Colombia: lugar de las disciplinas y disputa por la hegemonía de un saber. Revista de Estudios Sociales, 52, 134.

Haste, H. (1993). Morality, self, and sociohistorical context: The role of lay social theory. En G. Noam \& T. Wren (Eds.). The moral self (pp. 175207). Massachusetts: MIT Press Cambridge, MA. 
Haste, H. \& Abrahams, S. (2008). Morality, culture and the dialogic self: Taking cultural pluralism seriously. Journal of Moral Education, 37 (3), 377-394.

Herrera, M. C. \& Cristancho, J. G. (2013). En las canteras de Clío y Mnemosine: Apuntes historiográficos sobre el Grupo Memoria Histórica. Historia Crítica, 50, 193-210.

Herrera, M. C. \& Rodríguez, S. P. (2012). Historia, memoria y formación: Violencia sociopolítica y conflicto armado. Revista Colombiana de Educación, 62, 12-18.

Hess, D. E. (2009). Controversy in the classroom: The democratic power of discussion. Nueva York: Routledge.

Kitson, A. (2007). History teaching and reconciliation in Northern Ireland. En E. Cole (Ed.), Teaching the violent past. History education and reconciliation (pp. 123). Maryland: Rowman \& Littlefield.

León Rodriguez, N. \& Pérez Vargas, W. (2011). Sociales para pensar 9. Bogotá: Norma.

Lizarralde, M. (2012). Ambientes educativos y territorios del miedo en medio del conflicto armado: Estudio sobre escuelas del bajo y medio Putumayo. Revista Colombiana de Educación, 62, 21-39.

Maraboli, O. \& Wiesner, J. J. (2013). En J. E. Melo Pinzón (Ed.), Los caminos del saber. Sociales 9. Bogotá: Santillana.

McCully, A. (2012). History teaching, conflict and the legacy of the past. Education, Citizenship and Social Justice, 7 (2), 145-159.

Mendoza, C., \& Prieto, A. (2012). En C. A.,Maldonado y M. C. Ortiz (Eds.). Proyecto de ciencias sociales 9: Libro del estudiante. Bogotá: sM.

Nash, G.; Crabtree, C. \& Dunn, R. (1997). History on trial: Culture wars and the teaching of the past. Nueva York: Vintage.

Oglesby, E. (2007). Historical memory and the limits of peace education: Examining Guatemala's memory of silence and the politics of currículum design. En E. Cole (ed.). Teaching the violent past: History education and reconciliation (pp. 175-202). Maryland: Rowman \& Littlefield.

Pagès, J. (2003). Ciudadanía y enseñanza de la historia. Reseñas de Enseñanza de la Historia. Revista de la Apehun, 1, 11-42.

Raviv, A.; Oppenheimer, L. \& Bar-Tal, D. (eds.) (1999). How children understand war and peace: A call for international peace education. San Francisco: Jossey Bass.

Reardon, B. (1988). Comprehensive peace education: Educating for global responsibility. Nueva York: Teachers College Press.

Saldaña, J. (2012). The coding manual for qualitative researchers. Los Ángeles: Sage. 
Salomon, G. \& Nevo, B. (eds.) (2005), Peace education: The concept, principles, and practices around the world. Nueva York: Psychology Press.

Salomon, G. (2004). A narrative-based view of coexistence education. Journal of Social Issues, 60 (2), 273-287. doi:10.1111/j.00224537.2004.00118.x

Savenije, G.; Van Boxtel, C. \& Grever, M. (2014). Learning about sensitive history: "Heritage" of slavery as a resource. Theory \& Research in Social Education, 42 (4), 516-547.

Sears, A. (2011). Historical thinking and citizenship education: It is time to end the war. New Possibilities for the Past: Shaping history education in Canada, 344, 364.

Seixas, P. (Ed.) (2004). Theorizing historical consciousness. Toronto: University of Toronto Press.

Seixas, P. \& Morton, T. (2013). The big six: Historical thinking concepts. Toronto: Nelson Education.

Shaheed, F. (2013). Report of the special rapporteur in the field of cultural rights on the issue of writing and teaching of history, with a particular focus on history textbooks. United Nation General Assembly.

Shemilt, D. (1980). Evaluation study: Schools council history 13-16 project. Edinburgh: Holmes McDougall.

Sheppard, M.; Katz, D. \& Grosland, T. (2015). Conceptualizing emotions in social studies education. Theory \& Research in Social Education, 43 (2), 147-178.

Symcox, L. \& Wilschut, A. (2009). National history standards: The problem of the canon and the future of teaching history. Charlotte, North Carolina: Information Age.

Tulviste, P. \& Werstch, J. V. (1994). Official and unofficial histories: The case of Estonia. Journal of Narrative \& Life History, 4, 311-329.

Vélez, G. \& Herrera, M. (2014). Formación política en el tiempo presente: Ecologías violentas y pedagogía de la memoria. Nómadas, 41, 148-165.

Vygotsky, L. S. (1978). Mind in society: The development of higher psychological processes. Cambridge, Massachusetts: Harvard University Press.

Wenden, A. L. (2007). Educating for a critically literate civil society: Incorporating the linguistic perspective into peace education. Journal of Peace Education, 4 (2), 163-180. doi:10.1080/17400200701523561

Wertsch, J. V. (1997). Narrative tools of history and identity. Culture \& Psychology, 3 (1), 5-20.

Wertsch, J. V. (2004). Specific narratives and schematic narrative templates. Theorizing historical consciousness. 
Wills, M. E. (2015). Los tres nudos de la guerra colombiana: Un campesinado sin representación política, una polarización social en el marco de una institucionalidad fracturada, y unas articulaciones perversas entre regiones y centro. Comisión Histórica del Conflicto y sus Víctimas. Contribución al entendimiento del conflicto armado en Colombia (pp. 762-809). Bogotá: Centro Nacional de Memoria Histórica.

Wineburg, S. (2001). Historical thinking and other unnatural acts: Charting the future of teaching the past. Philadelphia: Temple University Press.

Zembylas, M. (2014). Theorizing "Difficult knowledge" in the aftermath of the "Affective turn": Implications for currículum and pedagogy in handling traumatic representations. Currículum Inquiry, 44 (3), 390-412. 